\title{
A PSEUDO-HERMAPHRODITE PRESENTING UNUSUAL FEATURES
}

\author{
By D. M. ForRest, F.R.C.S. \\ Surgical Registrar, Westminster Children's Hospital
}

Nearly all children whose sex at birth is indeterminate can eventually be classified into one of the following broad groups:-

(i) Pseudo-hermaphrodites, in whom the gonads are of one sex but the external genitalia and sometimes the duct apparatus show features of the opposite sex.

(ii) True hermaphrodites, having both ovarian and testicular tissue, are much less common.

(iii) Those patients, usually female, in whom masculinizing changes are produced solely by adrenal hyperplasia.

In the first and largest group, analysed in more detail by Gross and Meeker, ${ }^{1}$ are cases' presenting a confusing mixture of sexual apparatus which may, as in the present case, allow the development of remarkable syndromes.

\section{Case Report}

A child born in February 1943 was registered as a girl, but after six weeks was re-registered on the mother's initiative as a boy. He was seen at this age with acute retention of urine. Examination showed a short penis with hooded foreskin and a large bifid scrotum containing gonads. No doubt was felt as to his male sex. The retention was relieved by catheterization of the perineal urethra and did not recur.

At the age of two years he underwent an operation for correction of the hypospadias. An excellent result was obtained after re-operation to close a fistula.

When he was nine and a half years old he developed sudden severe central abdominal pain and vomited. Twenty-four hours later, on admission, there was marked tenderness in the right iliac fossa and a diagnosis of acute appendicitis was confidently made. At operation, free fluid was seen in the abdomen but the appendix appeared normal. When the pelvis was explored, structures resembling a small uterus with Fallopian tubes, broad ligaments and round ligaments were seen. The outer end of the right tube was dilated into a round inflamed mass, perforated and exuding creamy pus, This mass with the whole of the right tube was excised, but the remainder of the pelvic apparatus was not touched. Histology showed the specimen to be a pyo-salpinx but no gonadal tissue was identified.

Two months later biopsy of the right scrotal gonad showed it to be normal testis. No gonad could be found on the left at this time. Urinary excretion of ' 17 -ketosteroid was estimated as $3.6 \mathrm{mg}$. in 24 hours.

Six months later, when the patient was aged ten years, a further laparotomy was performed. Nothing resembling a gonad could be found in the left side of the abdomen. The structures in the recto-vesical pouch were removed. On the fourth post-operative day blood was passed from the perineum, presumably through a rudimentary vaginal orifice. Histology of the excised organs showed normal cervical and vaginal tissue.

The child was next seen at the age of eleven years, by which time the left testis was established in the scrotum and pubic hair was appearing.

At the age of twelve years the boy was rather obese and was embarrassed by mammary enlargement. The general distribution of fat and hair was, however, predominantly male. His psychological outlook was strongly masculine. Skin biopsy was performed and showed a chromosomal pattern of male type. The urinary excretion of 17 -ketosteroid was $5.7 \mathrm{mg}$. in 24 hours. He was given methyl testosterone in small dosage with improvement in the gynaecomastia.

He is now thirteen years old and is a welldeveloped youth (see figure). He has an erection of the penis about twice daily, though with slight chordee near the tip.

\section{Comment}

Great difficulty may be experienced in determining the sex of a child at birth, but usually, as in the present case, the external organs of one sex rapidly predominate, making the child's sex obvious after a few weeks. On occasion, however, the outward appearance may not be an accurate guide to the patient's ' true ' sex, compounded as this is of gonadal sex, chromosomal sex, accessory 


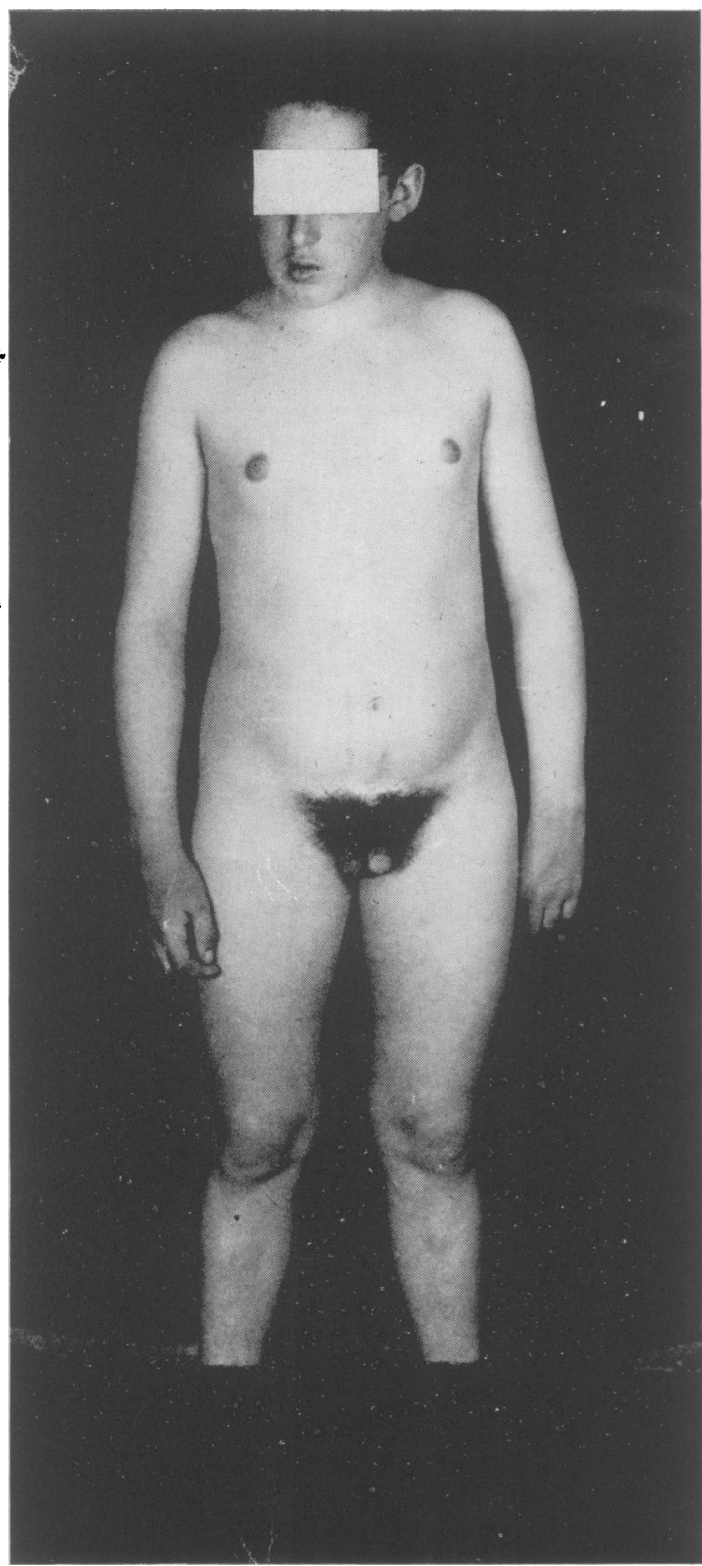

sex organs, hormonal balance, external appearance and, later, psychological outlook. It is, of course, our aim to allow the development of an individual in which all these components are compatible and, if possible, capable of full function.

In order to achieve this ideal it is necessary to take all these factors into consideration. Unfortunately, some of the more important characteristics do not show themselves until the approach of puberty so that in difficult cases a final decision may have to be long delayed.

Most reliance must be placed on the gonadal sex and this can only be established by biopsy, often after careful abdominal exploration and not omitting examination of scrotal organs which may prove to be labial ovaries or ovo-testes. If the accessory organs of the same sex as the gonads are present and well developed the decision is easy and organs of the opposite sex may be excised, but if they are absent or rudimentary it is sometimes necessary for the psychological bias to become clear, making allowance for the child's upbringing, before the wiser choice becomes obvious.

Estimations of urinary androgens are of some help after puberty, but at the time when they would be of most use they are usually equivocal. They should always be done, however, at the first opportunity, because in those cases in which abnormalities are due solely to adrenal hyperplasia increased androgen excretion can be detected at an early age.

Recently Barr and his follow-workers ${ }^{2}$ have shown that the chromosomal sex can be determined with ease and considerable accuracy. These workers are the first to point out, however, that in deciding the sex in which to bring up an individual, other factors must often carry more weight.

In the present case, little doubt was felt as to the male sex of the patient, and it was not until the age of nine years when he presented with a gynaecological condition that it was realized that he possessed female sex organs. Had this emergency not occurred their presence might never have been suspected. It is interesting to speculate on the number of males with a hypospadias who may be similarly equipped. Subsequent investigations of the child have all confirmed his predominant masculinity and there can be no doubt that it was correct to excise his female organs and bring him up as a boy.

\section{Summary}

A case of pseudo-hermaphroditism is presented in whom the presence of female sex organs led to a bizarre abdominal emergency.

The problems of determination of sex in infants are briefly discussed.

\section{Acknowledgment}

I wish to thank Mr. David Levi for permission to publish this case.

REFERENCES

I. GROSS, R. E., and MEEKER, I. A. (1955), Paediatrics, 16 3, 303-324.

2. MOORE, K. L., and BARR, M. L. (I955), Lancet, ii, 57. 